\title{
CORROSION EFFECT OF $20 \%$ NACL SOLUTION ON BASIC CARBON STRUCTURAL S235JR STEEL
}

\author{
Tomasz Lipinski \\ University of Warmia and Mazury in Olsztyn, Poland \\ tomaszlipinski.tl@gmail.com
}

\begin{abstract}
All structural steels offer economical properties of mean strength and low corrosion resistance. There are ferritic-perlitic steels and very often used as construction materials in industrial applications. The purpose of this article is to investigate corrosion resistance using weight loss and profile roughness parameters of typical structural steel in grade S235JR in $20 \% \mathrm{NaCl}$ solution in distilled water. Corrosion tests show that the tested steel in both corrosive environments is characterized through continuous corrosion. Roughness parameters for every of the research times determine the size of steel corrosion.
\end{abstract}

Keywords: steel, structural steel, carbon steel, corrosion, corrosion rate, profile roughness.

\section{Introduction}

Steel is the most popular constructional material. The mechanical, physical and chemical properties of low carbon steel are under the influence of different factors, including the chemical composition and manufacturing technology.The properties and practical applications of all constructional materials, including steel, are determined mostly by their microstructure. The structural low carbon steels have a ferritic-perlitic microstructure. The percentage of each microstructure phase shapes the properties of the steel. The microstructure depends on the manufacturing technology and heat treatments of steel. Corrosion resistance is an important factor of the quality and application of structural steels [1-12].

Low-carbon steel as a construction material is also very popular. Steels from this group have wide range of industrial applications, mainly as a welded material. The microstructure and properties of these steels are still tested to improve the quality. These steels are willingly used because they are cheap and well welded. Steel structures with low-carbon structural steel can be built by welding quickly at a low price, but still the main problem is their corrosion protection [13-16].

The influence of inner structural stresses caused by the corrosion notches as well as stresses resulting from production with stresses resulting from external load plays an important role in premature destruction of the construction by formation and development of initiation cracks and cracks. Structural stresses also depend on the percentage of each phase in the microstructure and their shape. Microstructure morphology is shaped in the process of manufacturing, heat treatment and welding processes. Corrosion processes are able to extract metal atoms from the metal lattice, which atoms during the process pass to corrosion products. Corrosion causing local diffusion of metal atoms is particularly dangerous [17-25]. The problem is huge because low-carbon structural steel is sensitive to corrosion. The corrosion rate first of all depends on different environment $[2 ; 5 ; 13 ; 20]$.

One of the corrosive environmental factors are chlorides. They are mainly found on the coast as an aerosol of sea water, and in large quantities in large industrial areas. Because of this structural steel has been often tested with $\mathrm{NaCl}$ on corrosion resistance $[14 ; 17 ; 18 ; 24]$.Having regard to the importance of the problem, this study was carried out to investigate the corrosion resistance of low carbon structural steel in $20 \% \mathrm{NaCl}$ water at ambient temperature.

\section{Materials and methods}

The experiment was performed on low carbon S235JR (1.0038) steel designation according to the EN 10025-2:2004 [26], plate thickness $t=5.00 \mathrm{~mm}$. The real chemical composition of the tested steel is presented in Table 1 .

Average mechanical properties at ambient temperature are presented in Table 2. The properties are according to the standard EN 10025-2:2004 [26].

Before the performed experiments, the specimens after mechanically cut off with an area of $13 \mathrm{~cm}^{2}(40 \times 10 \times 5 \mathrm{~mm})$ were successively polished with water paper to $R_{a}=0.32 \mu \mathrm{m}$, and next cleaned with $95 \%$ alcohol. 
Chemical composition of S235JRsteel

Table 1

\begin{tabular}{|c|c|c|c|c|c|c|c|c|}
\hline $\mathbf{C}$ & $\mathbf{S i}$ & $\mathbf{M n}$ & $\mathbf{P}$ & $\mathbf{S}$ & $\mathbf{C r}$ & $\mathbf{C u}$ & $\mathbf{N i}$ & $\mathbf{N}$ \\
\hline 0.19 & 0.22 & 0.90 & 0.03 & 0.04 & 0.03 & 0.02 & 0.02 & 0.01 \\
\hline
\end{tabular}

Table 2

Mechanical properties at ambient temperature of S235JRsteel

\begin{tabular}{|c|c|c|c|}
\hline $\boldsymbol{R}_{\boldsymbol{e} \boldsymbol{H}}$ & $\boldsymbol{R}_{\boldsymbol{m}}$ & $\boldsymbol{A}$ & $\boldsymbol{H B}$ \\
\hline $\mathrm{MPa}$ & $\mathrm{MPa}$ & $\%$ & $\mathrm{HB}$ \\
\hline 247 & 386 & 27 & 145 \\
\hline
\end{tabular}

The samples with ferritic-perlitic microstructure were tested in accordance with the standard dedicated for stainless steel PN EN ISO 3651-1 [27], corrosive media were represented by $20 \% \mathrm{NaCl}$.

The corrosion rate of S235JR steel measured in mm per year was calculated with the use of the below formula (1), measured in $\mathrm{g} \cdot \mathrm{m}^{-2}$ was calculated with the use the below formula (2):

$$
\begin{gathered}
r_{\text {corm }}=\frac{8760 \cdot m}{S \cdot t \cdot \rho}, \\
r_{\text {corg }}=\frac{10000 \cdot m}{S \cdot t},
\end{gathered}
$$

where $t$ - time of soaking in a corrosive solution of $20 \% \mathrm{NaCl}$ water solution, $\mathrm{h}$,

$S$ - surface area of the sample (starting value was assumed), $\mathrm{cm}^{2}$,

$m$ - average mass loss in solution (measured as difference of initial mass and mass after corrosion time), $\mathrm{g}$,

$\rho$ - sample density, $\mathrm{g} \cdot \mathrm{cm}^{-3}$.

The corrosion resistance of S235JR steel in $20 \%$ water solutionNaCl was tested using weight loss. The mass of the samples were measured by Kern ALT 3104AM digital laboratory precision scales with accuracy of measurement $0.0001 \mathrm{~g}$.

Profile roughness parameters were analyzed according to the PN-EN 10049:2014-03 standard (Measurement of roughness average Ra and peak count RPc on metallic flat products) by the Diavite DH5 profilometer.

\section{Results and discussion}

The microstructure of raw S235JR steel is presented in Fig. 1. The effect of hot rolling on the phase orientation presents the elongated ferrite phase (white area) at the background perlite (gray area). Next, the corrosion tests in $20 \%$ NaClwater solutionat ambient temperature for time 192 hours are presented in Fig. 2.

Profile roughness parameters of S235JR steel after the corrosion tests in $20 \% \mathrm{NaCl}$ are presented in Fig. 4 with: $R_{a}$ - arithmetical mean roughness value $(\mu \mathrm{m}), R_{p}-$ maximum roughness depth $(\mu \mathrm{m})$, $R_{q}$ - mean peak width $(\mu \mathrm{m}), R_{t}$ - total height of the roughness profile $(\mu \mathrm{m})$ for time range:48, 96, 144, 192, 240, 288, 336, 384 and 432 hours of soaking are presented in Fig. 5. The regression equations and correlation coefficients $r$ are presented in (3)-(6).

$$
\begin{gathered}
R_{a}=10^{-5} t^{2}+0.01024964 \cdot t+1.6738 \text { and } r=0.9970, \\
R_{q}=0.0067 \cdot t+2.9611 \text { and } r=0.9912, \\
R_{t}=7 \cdot 10^{-5} t^{2}+0.0012 \cdot t+17.905 \text { and } r=0.9889 \\
R_{p}=0.0198 \cdot t+16.636 \text { and } r=0.9810 .
\end{gathered}
$$




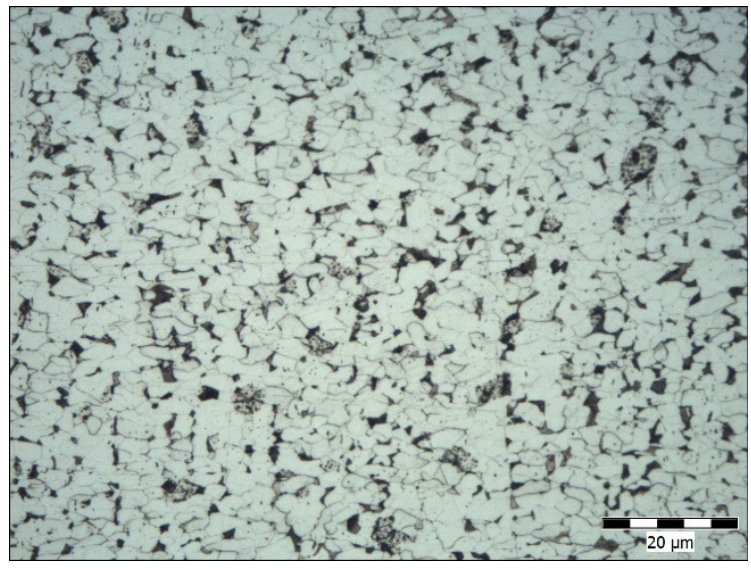

Fig. 1. Microstructure ofS235JR: light etched ferrite and dark etched perlite

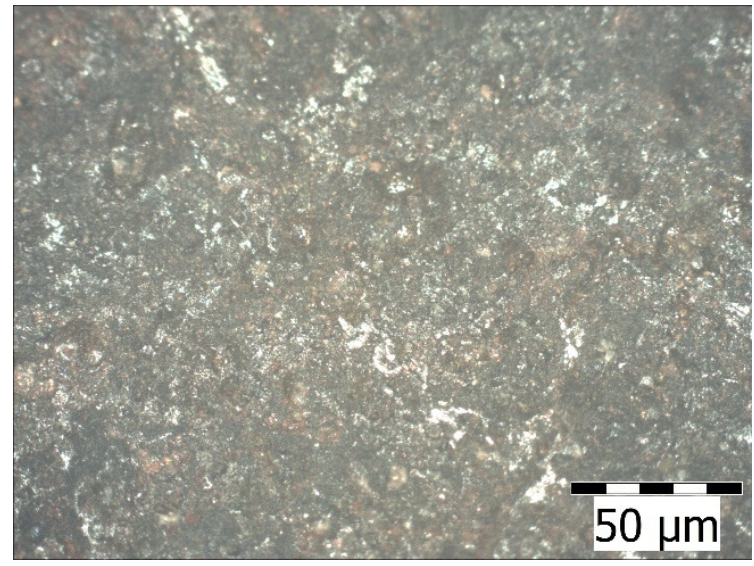

Fig. 2. Surface of S235JR after corrosion tests in $20 \%$ NaClwatersolutionat ambient temperature for time192 hours

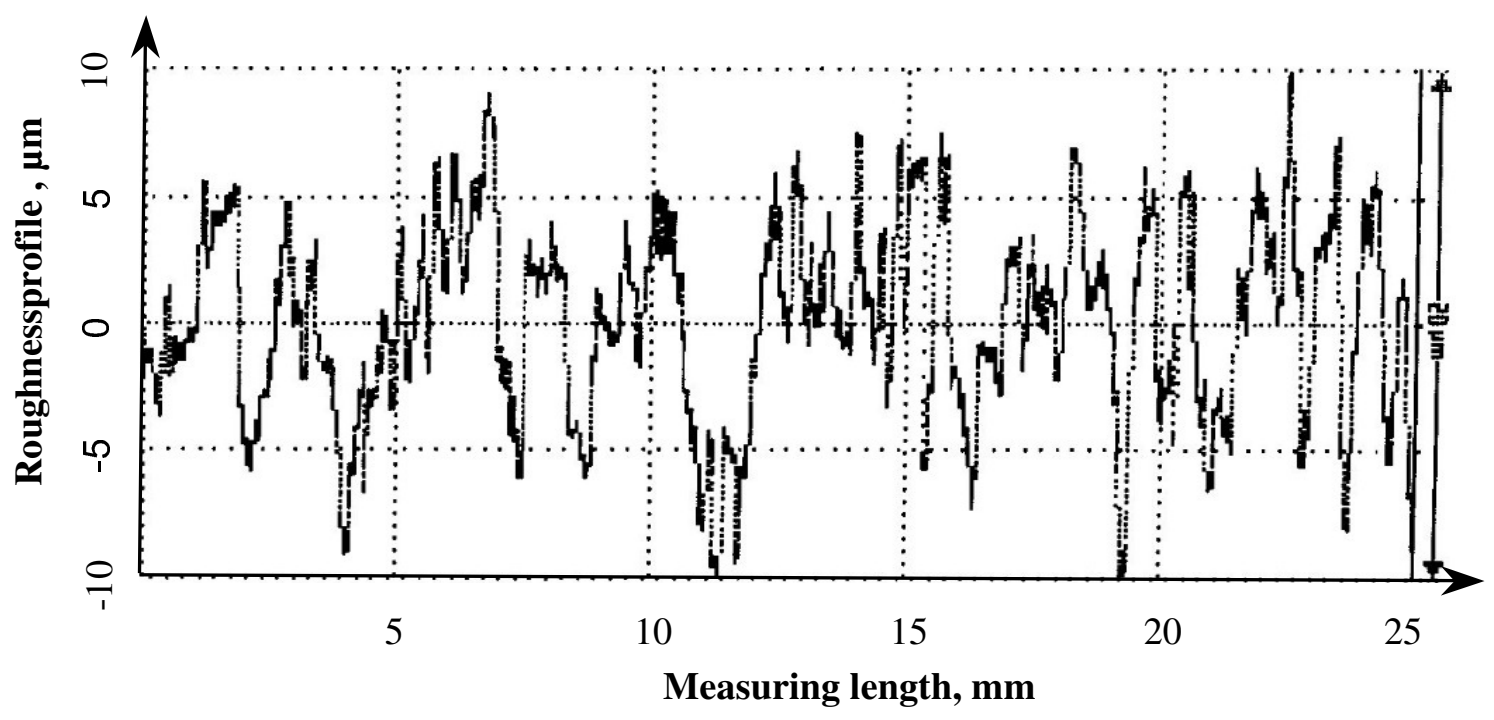

Fig. 3. Profile roughness of S235JR steel after corrosion tests in $20 \% \mathrm{NaCl}$ water solution at ambient temperature for time 192 hours

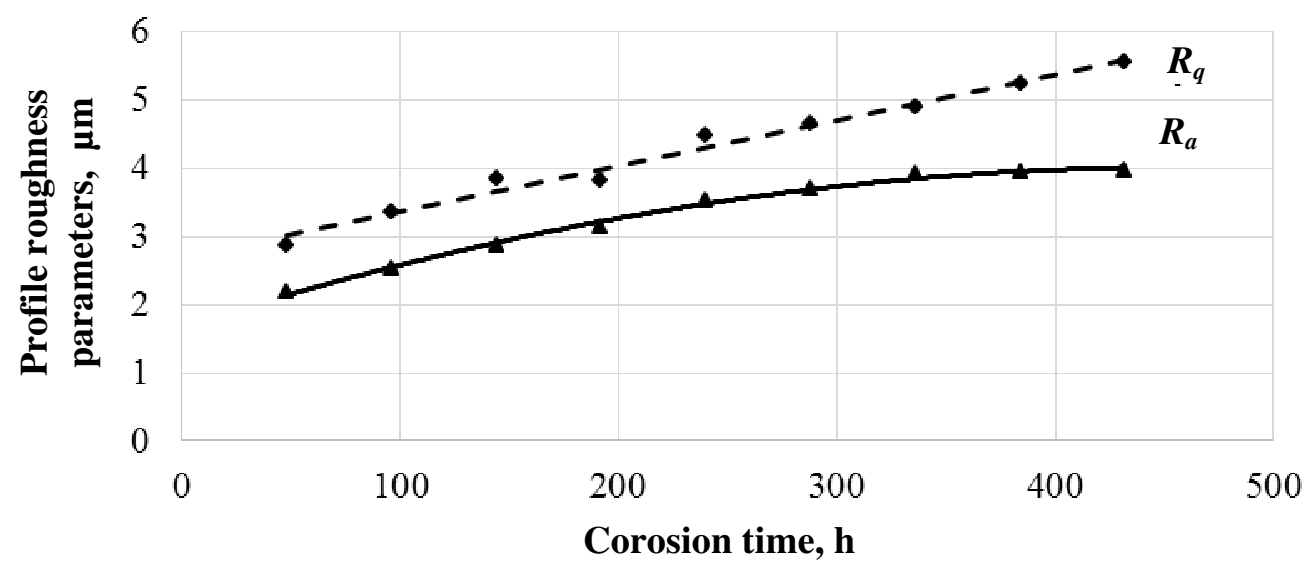

Fig. 4. Profile roughness of $\mathbf{S 2 3 5 J R}$ steel after corrosion tests in $20 \% \mathrm{NaCl}$ water solution at ambient temperature for different corrosion time: $R_{a}$ - arithmetical mean roughness value $(\mu \mathrm{m})$; $R_{q}$ - mean peak width $(\mu \mathrm{m})$ 


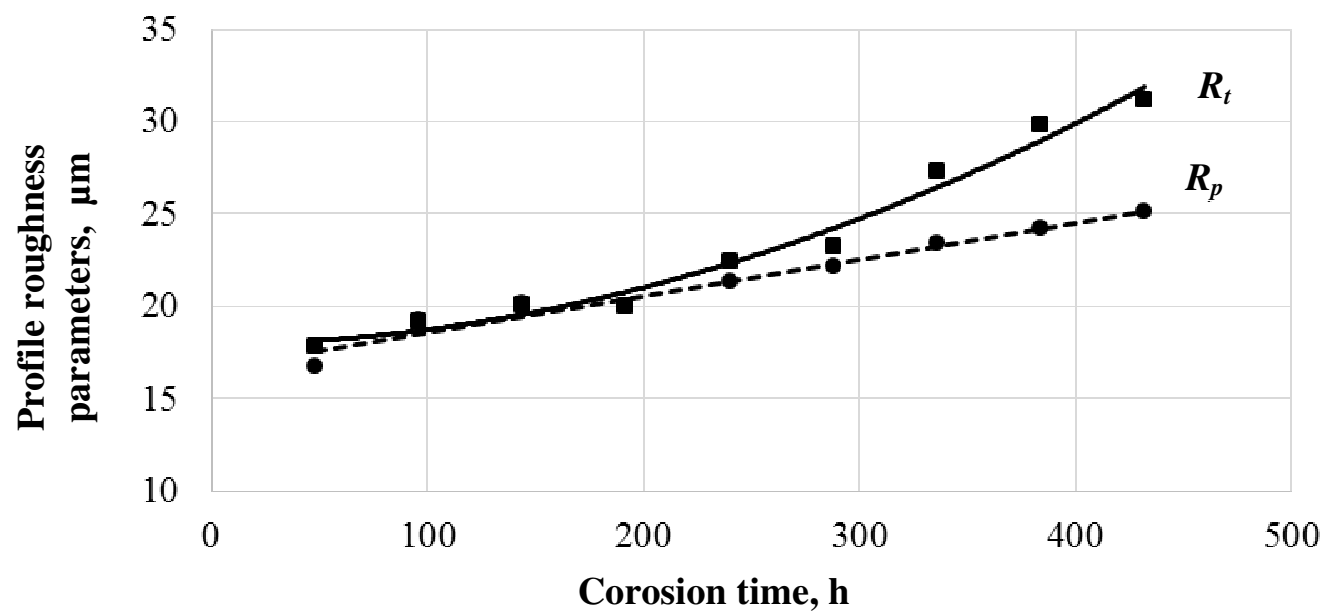

Fig. 5. Profile roughness of $\mathbf{S 2 3 5 J R}$ steel after corrosion tests in $20 \% \mathrm{NaCl}$ water solution at ambient temperature for different corrosion time: $R_{p}$ - maximum roughness depth $(\mu \mathrm{m})$;

$$
R_{t} \text { - total height of the roughness profile }(\mu \mathrm{m})
$$

The influence of the time of soakingthe S235JR structural steel in $20 \% \mathrm{NaCl}$ water solution nat ambient temperature on the relative mass loss $(R M L)$ is presented in Fig. 6, regression equation and the correlation coefficient $r$ in (7).

$$
R M L=0.0013 \cdot t+0.0492 \text { and } r=0.9995 .
$$

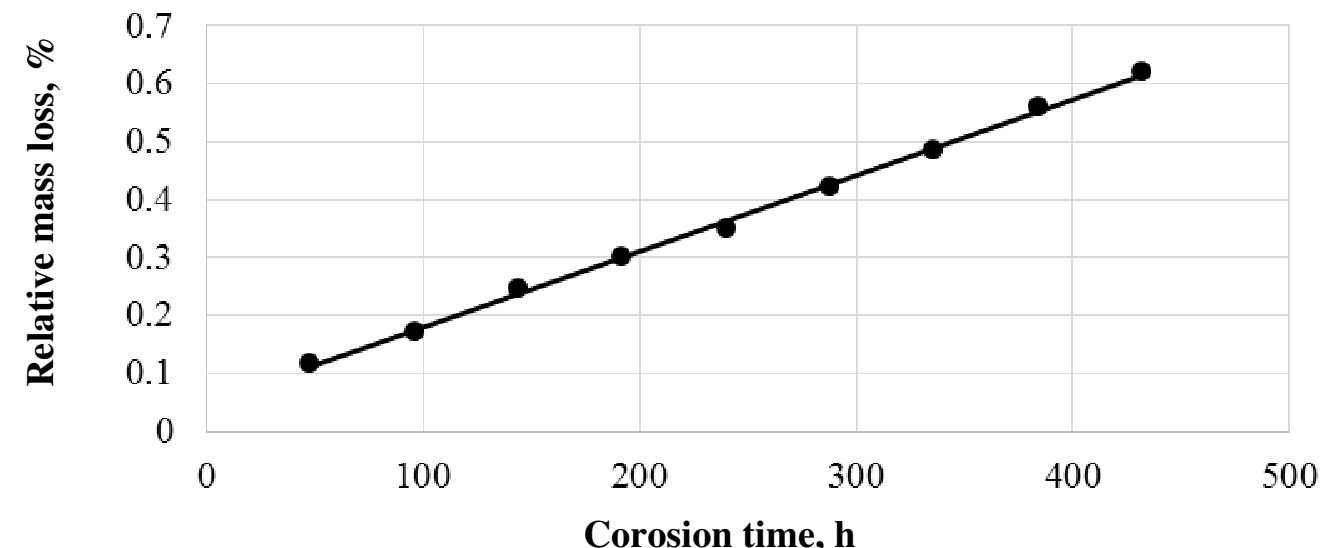

Fig. 6. Influence time on the relative mass loss $(R M L)$ at ambient temperature of S235JR structural steel of soaked in $20 \% \mathrm{NaCl}$ water solution

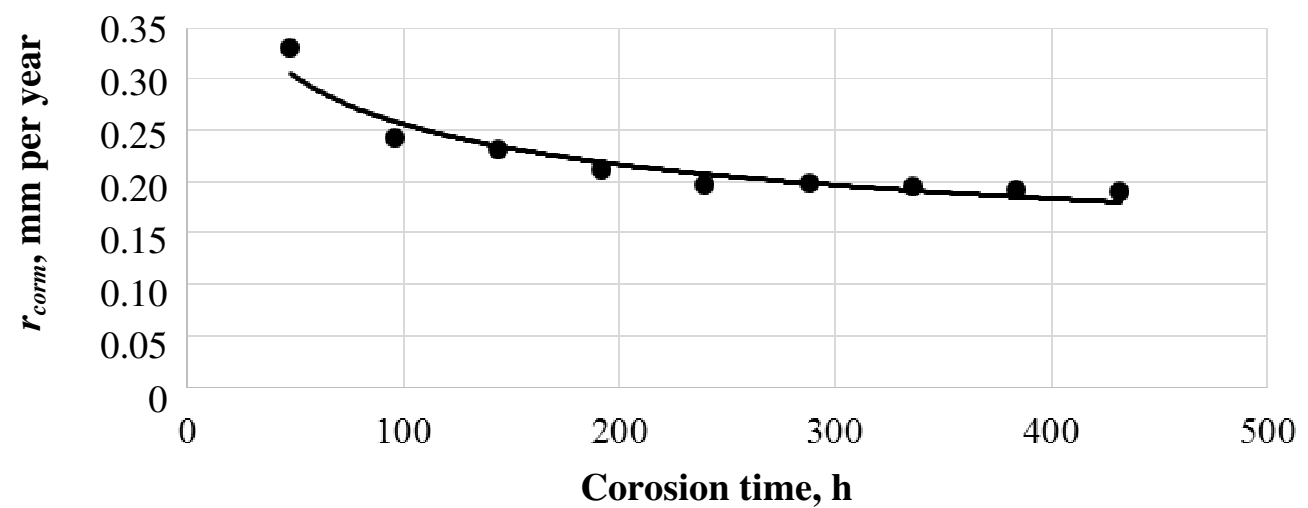

Fig. 7. Influence time of soaking S235JR structural steel in $20 \% \mathrm{NaCl}$ water solution at ambient temperature on the corrosion rate measured in $\mathrm{mm}$ per year 
The influence of the time of soaking S235JR structural steel in $20 \% \mathrm{NaCl}$ water solution at ambient temperature on the corrosion rate measured in $\mathrm{mm}$ per year is presented in Fig. 7, regression equation and the correlation coefficient $r$ in (8).

$$
R_{\text {corm }}=0.7730 \cdot t^{-0.24} \text { and } r=0.9624 \text {. }
$$

The influence of the time of soaking S235JR structural steel in $20 \% \mathrm{NaC}$ water solution at ambient temperature on the corrosion rate measured in gram per $\mathrm{m}^{2}$ is presented in Fig. 8, regression equation and the correlation coefficient $r$ in (9).

$$
R_{\text {corm }}=0.6938 \cdot t^{-0.24} \text { and } r=0.9624 \text {. }
$$

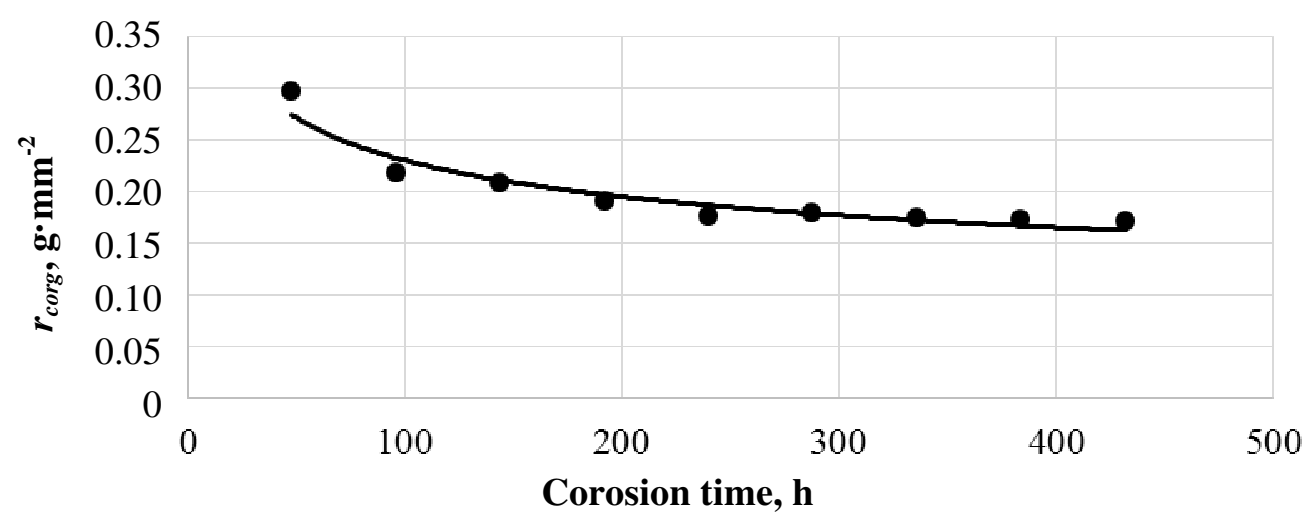

Fig. 8. Influence time of soaking S235JR structural steel in $20 \% \mathrm{NaCl}$ water solution at ambient temperature on the corrosion rate measured in gram per $\mathbf{m}^{2}$

\section{Conclusions}

1. The results of the research show that the weight loss of S235JR steel soaking in $20 \% \mathrm{NaCl}$ water solution at ambient temperature is proportional to the time of corrosion. The roughness of the sample increases, but the corrosion rate measured as a corrosion velocity decreases with time.

2. Profile roughness parameters such as $R_{q}$ - mean peak width and $R_{p}$ - maximum roughness depth increase linearly and with the increase of the time of the corrosion process. $R_{t}-$ total height of the roughness profile increase grows in accordance with developments of the polynomial function second degree with increase of the time, while $R_{a}$ parameters - arithmetical mean roughness value in the first stage of corrosion to about 350 hours intensively, but then its growth rate decreases.

3. Based on the course of the roughness profiles for each of the test times, it is possible to determine the velocity of corrosion of the test steel at any time.

4. The obtained corrosion velocity equations can be used to model the course of corrosion processes.

\section{References}

1. Szabracki P., Lipiński T., Influence of sigma phase precipitation on the intergranular corrosion resistance of X2CrNiMoN25-7-4 super duplex stainless steel, in: 23rd International Conference on Metallurgy and Materials METAL 2014, pp. 476-481.

2. Dudek A., Wrońska A., Adamczyk L. Surface remelting of 316 L+434 L sintered steel: microstructure and corrosion resistance. J Solid State Electr 18/11, 2014, pp. 2973-2981.

3. Szabracki P., Lipiński T., Effect of aging on the microstructure and the intergranular corrosion resistance of X2CrNiMoN25-7-4 duplex stainless steel, Sol St Phen 203-204, 2013, pp. 59-62.

4. Selejdak J., Ulewicz R., Ingaldi M. The evaluation of the use of a device for producing metal elements applied in civil engineering, in: 23rd International Conference on Metallurgy and Materials METAL 2014, pp. 1882-1888.

5. Scendo M., Radek N., Trela J. Influence of laser treatment on the corrosive resistance of Wc-Cu coating produced by electrospark deposition. Int. J. Electrochem. Sc 8, 2013, pp. 9264-9277.

6. Ulewicz R., Quality control system in production of the castings from spheroid cast iron. 42(1), 2003, pp. 61-63. 
7. Włodarczyk R. Dudek A. Nitkiewicz Z. Corrosion Analysis Of Sintered Material Used For LowTemperature Fuel Cell Plates .Archives of Metallurgy and Materials56(1), 2011, pp. 181-186.

8. JonštaP., VáňováP., BrožováS., PustějovskáP., SojkaJ., JonštaZ., IngaldiM. Hydrogen Embrittlement Of Welded Joint Made Of Supermartensitic Stainless Steel In Environment Containing Sulfane. Archives of Metallurgy and Materials 61(2), 2016, pp.709-711.

9. Ulewicz R., Nový F., Selejdak J., Fatigue Strength of Ductile Iron in Ultra-High Cycle Regime, Advanced Materials Research 874, 2014, pp. 43-48.

10. Ulewicz R. Hardening of Steel X155CrVMo12-1 Surface Layer. Journal of the Balkan Tribological Association21(1), 2015, pp.166-172.

11. Lipiński T. Corrosion Resistance of 1.4362 Steel in Boiling $65 \%$ Nitric Acid. Manufacturing Technology 16(5), 2016, pp. $1004-1009$.

12. Zatkalíková V., Markovičová L., Chalupová M. Corrosion resistance of Cr-Ni-Mo Stainless Steel in Chloride and Fluoride Containing Environment Manufacturing Technology 16(5), 2016, pp. $1193-1198$.

13. Thompson N.G., Yunovich M., Dunmire D. Cost of corrosion and corrosion maintenance strategies, Corros. Rev. 25, 2007, pp. 247-262.

14. Kocańda D., Mierzyński J., Mroziński S., Torzewski J.Fatigue Behaviour of S235JR Steel after Surface Frictional-Mechanical Treatment in Corrosive Environment. Key Engineering Materials, 598, 2014, pp. 105-112,

15. Santana Rodriquez, J.J., Gonzalez Gonzalez, J.E. Identification and formationof green rust 2 as an atmospheric corrosion product of carbon steel in marineatmospheres. Mater. Corros. 57 (5), 2006, pp. 411-417.

16. Machuca L.L., Jeffrey R., Melchers R. E. Microorganisms associated with corrosion of structural steel in diverse atmospheres. International Biodeterioration\& Biodegradation 114, 2016, pp. 234243.

17. Ladan M., BasirunW. J., KaziS. N., Rahman F. A. Corrosion protection of AISI 1018 steel using Co-doped $\mathrm{TiO} 2 /$ polypyrrole nanocomposites in $3.5 \% \mathrm{NaCl}$ solution. Materials Chemistry and Physics 192, 2017,pp. 361-373.

18. Alizadeh M., Bordbar S. The influence of microstructure on the protectiveproperties of the corrosion product layer generated on the welded API X70steel in chloride solution, Corrosion Science 70, 2013, pp. 170-179.

19. Al-DuheisatS. A., El-Amoush A.S. Effect of deformation conditions on the corrosion behavior of the low alloy structural steel girders. Materials and Design 89, 2016, pp. 342-347.

20. Uhlig H.H., Revie R.W. Corrosion and corrosion control, 3rd Edition, John Wiley and Sons, 1985, pp. 174.

21. Naveen E., Ramnath B. V., ElanchezhianC. , Mohamed Nazirudeen S.S. Influence of organic corrosion inhibitors on pickling corrosion behaviour of sinter-forged $\mathrm{C} 45$ steel and $2 \% \mathrm{Cu}$ alloyed C45 steel. Journal of Alloys and Compounds 695, 2017,pp. 3299-3309.

22. Chandramouli R., Kandavel T.K., ShanmughaSundaram D., Ashok Kumar T. Deformation, densification and corrosion studies on sintered P/M plain carbon steel preforms, Material Design 28, 2007, pp. 2260-2264.

23. Zhang J., Gong X.L., Yu H.H., Du M. The inhibition mechanism of imidazoline phosphate inhibitor for Q235 steel in hydrochloric acid medium, Corrosion Sci. 53, 2011, pp. 3324-3330.

24. Pradityana A., Sulistijono, Shahab A. Effectiveness of myrmecodiapendans extract as ecofriendly corrosion inhibitor for material API 5L grade B in 3,5\% NaCl solution," Advanced Material Research 789, 2013, pp. 484-491.

25. El-EtreA. Y., Abdallah M. Natural honey as corrosion inhibitor for metals and alloys. II. C-steel in high saline water. Corrosion Science42(4), 2000, pp. 731-738.

26. EN 10025-2:2004. Hot rolled products of structural steels - Part 2: Technical delivery conditions for non-alloy structural steel.

27. PN EN ISO 3651-1, Determination of resistance to intergranular corrosion of stainless steels. Part 1: Austenitic and ferritic-austenitic (duplex) stainless steels. Corrosion test in nitric acid medium by measurement of loss in mass (Huey test). 